\title{
Structure of southeastern Antarctic Peninsula ice shelves and ice tongues from synthetic aperture radar imagery
}

\author{
K.C. JEZEK, ${ }^{1}$ H.X. LIU $^{2}$ \\ ${ }^{1}$ Byrd Polar Research Center, The Ohio State University, 1090 Carmack Road, Columbus, Ohio 43210-1002, USA \\ E-mail: jezek@iceberg.mps.ohio-state.edu \\ ${ }^{2}$ Department of Geography, Texas A\&M University, College Station, Texas 77843-3147, USA
}

\begin{abstract}
Examination of synthetic aperture radar data collected over the southeastern Antarctic Peninsula shows that features sometimes mapped as ice shelves are more likely composed of numerous ice tongues interspersed within a matrix of fast ice and icebergs. The tongues are formed by the seaward extension of numerous small mountain glaciers that drain from the Antarctic Peninsula. Once afloat, the tongues intermingle with a matrix of fast ice and brash. Examination of 1997 RADARSAT-1 image mosaics shows that southeastern Antarctic Peninsula composite-ice shelves covered an area of about $3500 \mathrm{~km}^{2}$. Like ice tongues around the rest of Antarctica, these features are highly fragmented and likely to be susceptible to mechanical failure. One such composite shelf, located between New Bedford and Wright Inlets, was observed to decrease in area by $1200 \mathrm{~km}^{2}$ between 1997 and 2000 .
\end{abstract}

\section{INTRODUCTION}

Mercer (1978) postulated that Antarctic ice shelves would be the component of the Antarctic glacier system most responsive to 'greenhouse' warming. He predicted a southerly retreat of ice-shelf margins, starting with the ice shelves in the Antarctic Peninsula (Fig. 1). His ideas seem especially prescient given the rapid disintegration of the Wordie Ice Shelf during the 1980s (Doake and Vaughan, 1991), retreat of the Wilkins and George VI Ice Shelves (Lucchitta and Rosanova, 1998) and retreat and catastrophic collapse of the Larsen A ice shelf in 1995 (Skvarca, 1993; Rott and others, 1996; Vaughan and Doake, 1996) and the Larsen B ice shelf in 2002 (MacAyeal and others, 2003).

Here we use RADARSAT Antarctic Mapping Project (RAMP) image mosaics to examine the geography and physical properties of southeastern Antarctic Peninsula ice shelves and ice-filled embayments. In this paper, we show that several of these embayments are filled with a mixture of glacier-fed ice tongues, icebergs and fast ice. This physical composition is suggestive of a an incipient phase of ice-shelf development (Barkov, 1985, p.116-123) that is different from the developed stage of the more northerly Larsen A, B and $C$ ice shelves. We discuss the physical characteristics of the ice-filled embayments and describe changes in ice coverage during the 3 year interval between RAMP observations.

\section{ANALYSIS}

We conducted a careful inspection of the morphology of coastal ice around the continent, using the radiometrically calibrated RAMP $25 \mathrm{~m}$ resolution synthetic aperture radar (SAR) mosaic (Fig. 1) (Jezek, 1999). This high-resolution imagery allowed us to examine relatively fine-scale features (tens of meters). Moreover, we discriminated between pack ice, fast ice and glacier ice, partly because each of these ice types scatters microwave radiation differently. For example, new sea ice is often quite dark in SAR imagery because of its smooth surface and high dielectric permittivity (Onstott, 1992). Ice shelves are often quite bright during the winter months because refrozen meltwater causes the upper layers of the snow and firn to be infused with ice lenses and ice layers that are very effective microwave scatterers. In fact the 'percolation zone' on the ice sheet, where melt features such as ice lenses and layers are common, is one of the brightest radar targets on Earth (Jezek and others, 1994). The relationship between melt and radar reflectivity is well illustrated by Liu and others (2005), who compute the spatial extent of melt events on the Antarctic ice sheet and demonstrate the high correlation of melt occurrence and bright radar backscatter in coastal regions.

We used a two-fold approach to study the coastal areas. First, we developed a coastline-mapping algorithm that relied on the differences in scattering properties between the different ice types to automatically discriminate between glacier ice and other materials. Here, we define the coastline as the boundary between ocean (which may be

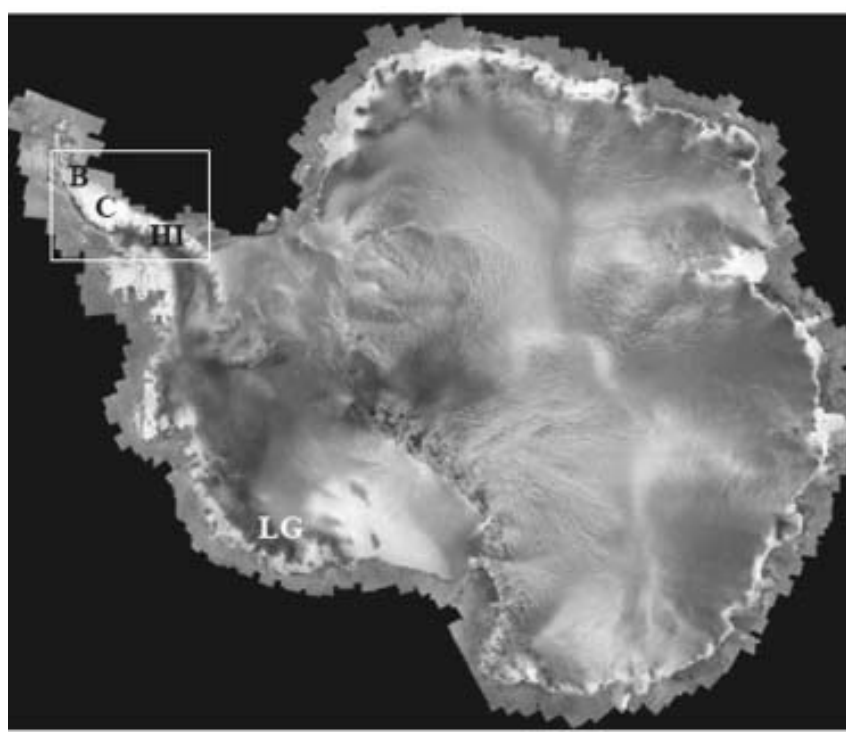

Fig. 1. RAMP mosaic of Antarctica. The white box encloses the Antarctic Peninsula study area. The locations of the Larsen B ice shelf (B), Larsen $C$ ice shelf $(\mathrm{C})$ and Hilton Inlet $(\mathrm{HI})$ are notated. The location of Land Glacier (LG) is also identified. 


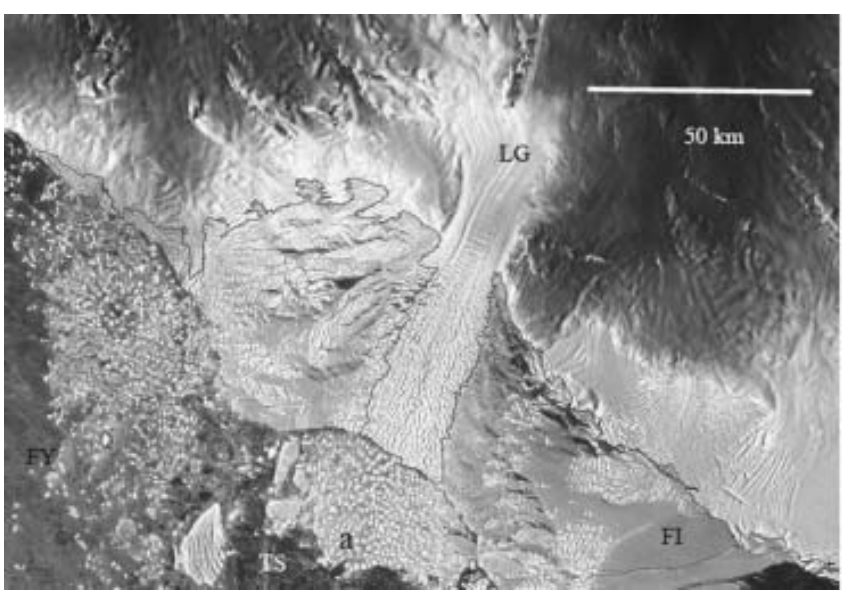

Fig. 2. Land Glacier (LG), Marie Byrd Land. The thin black line is the coastline mapped using the automatic extraction algorithm. The numerous small icebergs off the snout of the ice tongue (a) are square to rectangular with sides of about $0.8-1.5 \mathrm{~km}$. A matrix of fast ice (FI) and icebergs surrounds much of the ice tongue. Firstyear (FY) and thin (TS) sea ice is observed farther seaward.

sea-ice covered) and Antarctica's glacier ice and coastal rocky outcrops. The algorithm worked satisfactorily in most locations (Liu and Jezek, 2004). Of course, the algorithm does not work perfectly everywhere and there are complications that can cause confusion. Consequently, we used the automatic coastline as a reference and then did a manual inspection of the coastal region. For example, using visual discrimination based on texture, we edited the seaward extent of brash ice, which forms from broken bits of fast ice and icebergs accumulated in the leeward zones of small embayments. It can appear quite bright, causing the algorithm to misidentify this region as ice shelf.

Ice tongues are also places where the algorithm can become confused and indeed where it is difficult for the human observer to define a coastline. Land Glacier (Fig. 2) is a good example. Here, the outflow of ice from the interior extends seaward along a fractured tongue. The dispersal of kilometer-sized icebergs from the tongue is a slow process that is further retarded by what appears to be fast ice that glues the iceberg fragments into a matrix. It is difficult to determine visually when and where icebergs are physically decoupled from the flow.

We anticipated that, unlike the task of mapping Land Glacier, mapping the coastal boundary separating land and land ice from ocean and sea ice of the eastern Antarctic Peninsula would be relatively simple. Numerous coastline estimates exist (e.g. ADD Consortium, 2000) and most show that the ice front is a reasonably smooth, continuous and well-defined boundary separating ocean and ice. We were surprised to find that the actual situation was rather more complicated along the southeastern flank of the Antarctic Peninsula. Figure 3 shows a portion of the eastern Antarctic Peninsula extending from Anthony Glacier to Wright Inlet. The black line is the automatically extracted coastline and it agrees well with other estimates including British Antarctic Survey (BAS) maps (Series BAS 250, Edition 1-D.O.S. 1976: SR 19-20/12. 1976; SR 19-20/16) that show much the same position of the coastline from just north of Clifford Glacier to Hilton Inlet but at a much earlier time. The red line is our new interpretation of the coastline and is intended to delimit the boundary separating primarily glacier ice from sea-ice

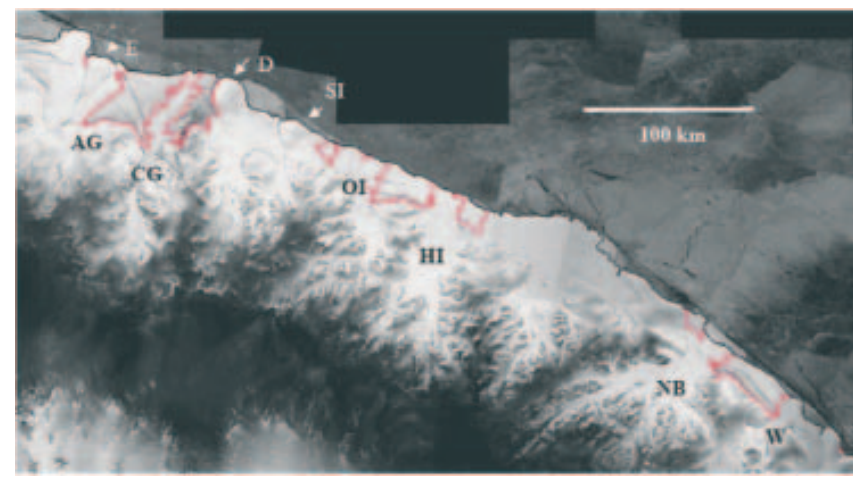

Fig. 3. Enlargement showing the southeastern Antarctic Peninsula. For geographical reference, Hilton Inlet (HI) is identified in Figure 1. Black line is the conventional interpretation of the coastline. Orange line is the reinterpretation based on the RAMP mosaic. Locations are: Anthony Glacier (AG), Clifford Glacier (CG), Oddom Inlet $(\mathrm{OI})$, New Bedford Inlet (NB) and Wright Inlet (W). Ewing (E), Dolleman (D) and Steele (SI) Islands are ice-covered.

types or open ocean. Ice tongues jut seaward from the spine of the peninsula and characterize this interpretation of the coastline. The ice tongues are clearly visible, along with small ice-covered islands such as Dolleman and Steele Islands, which are probably holding back some of the advancing glacier ice. The difference in ice-shelf area between previous coastline estimates and our new interpretation is about $3500 \mathrm{~km}^{2}$.

Figures 4 and 5 illustrate in more detail that at least the southeastern flank of the Antarctic Peninsula is characterized by fast ice and ice tongues, rather than purely glacierfed ice shelves. The upper panel in Figure 4 shows two well-defined ice tongues flowing from New Bedford and Wright Inlets. Like Land Glacier, the ice tongues are fractured. A band of fast ice separates them. We know this is fast ice rather than ice shelf, because of the presence of numerous icebergs in the ice matrix that are distributed on both sides of long cracks that span the region between the ice tongues.

These characteristics are even more graphically illustrated in Figure 5, which shows the ice tongue from Anthony Glacier bending around Ewing Island. The ice tongue from Clifford Glacier is highly fractured, the shape is irregular and the tongue itself appears to be nearly ready to break free from the glacier. The matrix of fast ice is again evident in the area between the tongues.

We speculate that portions of the ice margin in the southeastern Antarctic Peninsula are probably mechanically weak. Like other ice tongues around the continent (Holdsworth, 1985), we expect these to eventually break under wind and wave action and fragment into numerous small icebergs. We think that the peninsula ice tongues are partially strengthened by the surrounding matrix of fast ice (Holdsworth, 1982) and the confining influence of icecovered islands, but not sufficiently to allow consolidated ice shelves to form in the embayments. The transient nature of the ice filling the small embayments is illustrated by the lower image in Figure 4 which shows a 2000 RADARSAT image overlain with the same coastline position displayed in the upper image. Between 1997 and 2000 the embayment was swept free of approximately $1200 \mathrm{~km}^{2}$ of ice 

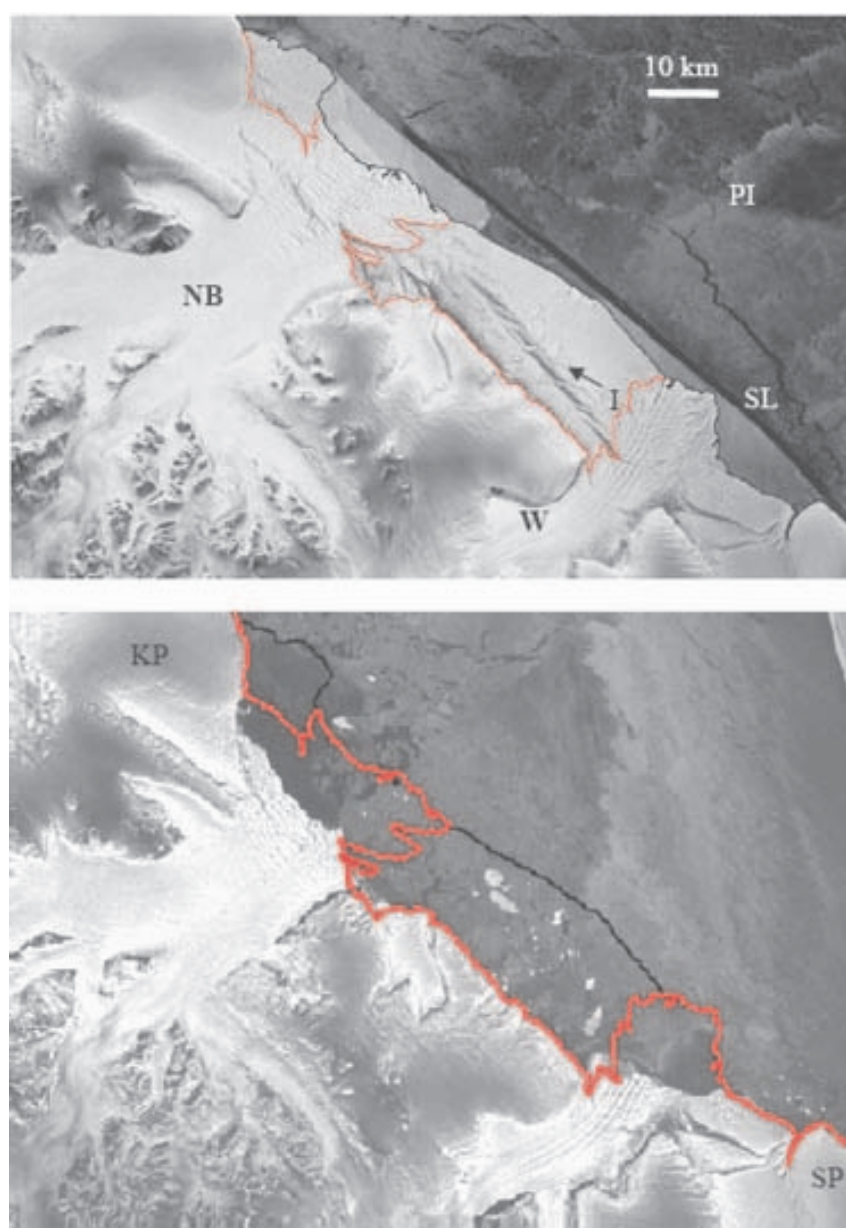

Fig. 4. (a) Ice tongues within New Bedford (NB) and Wright (W) Inlets observed in 1997. Small icebergs (I) are evident in the fast ice separating the two ice tongues. The icebergs and blocks on the ice tongues have rectangular dimensions of about $1.5 \mathrm{~km}$ long by $0.5 \mathrm{~km}$ wide, similar to those observed on Land Glacier. Pack ice (PI) and a shore lead (SL) are also seen. (b) The same area imaged in 2000 with the conventional (black) and 1997 reinterpreted coastlines (orange) overlain on the images. Kemp (KP) and Smith (SP) Peninsulas are labeled.

tongue and fast ice, an area roughly equivalent to the ice shelf lost during the 1995 break-up of Larsen A ice shelf (Rott and others, 1996). Notice that our estimated landward boundary of the 1997 fast ice coincides closely with the observed coastline between the ice tongues in 2000 and subsequent to the discharge event. The episodic nature of ice discharge events between the Kemp and Smith Peninsulas is suggested by the similarity between the 2000 RADARSAT ice front and the ice front marked on the BAS map compiled by Rowley and others (1992) which shows the 1978 New Bedford Inlet ice margin and the 1973 Wright Inlet margin.

\section{DISCUSSION}

Our analysis of Antarctic Peninsula ice shelves leads us to reclassify features on the southeastern flank of the peninsula as a combination of glacier ice tongues and fast ice. In Koenig and others' (1952) terminology, developed for comparably sized Arctic ice shelves (Jeffries, 2002), these could be referred to as composite-ice shelves. The composite-ice shelves discussed in this paper are characterized by

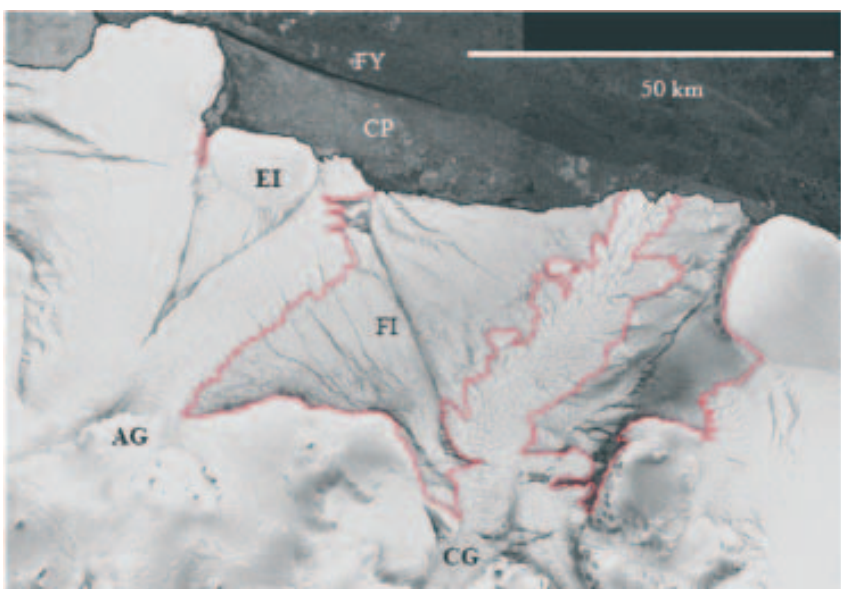

Fig. 5. Ice tongues from Anthony (AG) and Clifford (CG) Glaciers separated by fast ice (FI) that is cross-cut by leads. Individual blocks in the tongues have dimension on the order of $1-2 \mathrm{~km}$. The flow from Anthony Glacier bifurcates around Ewing Island (EI). The Clifford Glacier ice tongue appears ready to break free, as suggested by the large crack near the identifying mark (CG) on the image. A shore lead separates first-year ice (FY) from more consolidated pack (CP).

serrated ice tongues that merge with the fast ice. Based on our re-analysis, the glacier-charged ice-shelf area of the peninsula in 1997 is reduced by about $3500 \mathrm{~km}^{2}$, compared with the previous estimates.

Complex fracture patterns segment the ice tongues into blocks with dimensions ranging from about 0.5 to $1.5 \mathrm{~km}$ (Figs 4 and 5). The highly fractured ice tongues are mechanically weaker than consolidated ice shelves and so are probably more susceptible to sudden calving when forced by storm-wave interactions, long-period ocean swell or extreme tides (Holdsworth, 1985). Calving rates may also increase during the Antarctic Peninsula summer melt period in a fashion similar to that proposed by Sohn and others (1998) who offered melting as an explanation for the seasonal migration of the fractured, floating terminus of Jakobshavn Isbræ, Greenland.

\section{CONCLUSIONS}

Using an automatically derived coastline as a guide, we have reinterpreted the position of the coastline along the southeastern Antarctic Peninsula using a calibrated SAR mosaic. We find that many areas identified as ice shelves on earlier maps are better defined as composite-ice shelves, which are made up of a complex amalgam of glacier ice tongues, icebergs and fast ice. Retaining only the area of glacier-charged ice tongues within the composite-ice shelves reduces the total ice-shelf area about the peninsula by about $3500 \mathrm{~km}^{2}$. We propose that the composite-ice shelves are mechanically weak because of their distinctive and complex patterns of surface crevassing and rifting. We found that one such composite shelf retreated by about $1200 \mathrm{~km}^{2}$ over a 3 year period.

\section{ACKNOWLEDGEMENTS}

This research was supported by a grant from NASA's Polar Oceans and Ice Sheets Program. We thank three anonymous reviewers for many helpful comments. 


\section{REFERENCES}

ADD Consortium. 2000. Antarctic Digital Database, Version 3.0: database, manual and bibliography. Cambridge, Scientific Committee on Antarctic Research.

Barkov, N.I. 1985. Ice shelves of Antarctica. Rotterdam, A.A. Balkema.

Doake, C.S.M. and D.G. Vaughan. 1991. Rapid disintegration of the Wordie Ice Shelf in response to atmospheric warming. Nature, 350(6316), 328-330.

Holdsworth, G. 1982. Dynamics of Erebus Glacier tongue. Ann. Glaciol., 3, 131-137.

Holdsworth, G. 1985. Some effects of ocean currents and wave motion on the dynamics of floating glacier tongues. Antarctic Res. Ser., 43, 253-271.

Jeffries, M.O. 2002. Glaciers of the Arctic islands: Ellesmere Island ice shelves and ice islands. U.S. Geol. Surv. Prof. Pap. 1386-J-1, J147-J164.

Jezek, K.C. 1999. Glaciological properties of the Antarctic ice sheet from RADARSAT-1 synthetic aperture radar imagery. Ann. Glaciol., 29, 286-290.

Jezek, K.C., P. Gogineni and M. Shanableh. 1994. Radar measurements of melt zones on the Greenland ice sheet. Geophys. Res. Lett., 21(1), 33-36.

Koenig, L.S., K.R. Greenaway, M. Dunbar and G. Hattersley-Smith. 1952. Arctic ice islands. Arctic, 5(2), 67-103.

Liu, H. and K.C. Jezek. 2004. A complete high-resolution coastline of Antarctica extracted from orthorectified Radarsat SAR imagery. Photogramm. Eng. Remote Sens., 70(5), 605-616.
Liu, H., L. Wang and K. Jezek. 2005. Wavelet-transform based edge detection approach to derivation of snowmelt onset, end and duration from satellite passive microwave measurements. Int. J. Remote Sensing. 26(21), 4639-4660.

Lucchitta, B.K. and C.E. Rosanova. 1998. Retreat of northern margins of George VI and Wilkins Ice Shelves, Antarctic Peninsula. Ann. Glaciol., 27, 41-46.

MacAyeal, D.R., T.A. Scambos, C.L. Hulbe and M.A. Fahnestock. 2003. Catastrophic ice-shelf break-up by an ice-shelf-fragmentcapsize mechanism. J. Glaciol., 49(164), 22-36.

Mercer, J.H. 1978. West Antarctic ice sheet and $\mathrm{CO}_{2}$ greenhouse effect: a threat of disaster. Nature, 271(5643), 321-325.

Onstott, R. 1992. SAR and scatterometer signatures of sea ice. In Carsey, F.D. and 7 others, eds. Microwave remote sensing of sea ice. Washington, DC, American Geophysical Union, 73-104.

Rott, H., P. Skvarca and T. Nagler. 1996. Rapid collapse of northern Larsen Ice Shelf, Antarctica. Science, 271(5250), 788-792.

Rowley, P.D., K.S. Kellogg, P.L. Williams, C.F.H. Willan and J.W. Thompson. 1992. Geological map, southern Palmer Land and eastern Ellsworth Land: British Antarctic Survey series BAS 500G, sheet 6, scale 1:500 000. Cambridge, British Antarctic Survey.

Skvarca, P. 1993. Fast recession of the northern Larsen Ice Shelf monitored by space images. Ann. Glaciol., 17, 317-321.

Sohn, H.G., K.C. Jezek and C.J. van der Veen. 1998. Jakobshavn Glacier, West Greenland: thirty years of spaceborne observations. Geophys. Res. Lett., 25(14), 2699-2702.

Vaughan, D.G. and C.S.M. Doake. 1996. Recent atmospheric warming and retreat of ice shelves on the Antarctic Peninsula. Nature, 379(6563), 328-331. 